by Haoyu Zhu ${ }^{1,3,4}$, Dongsheng Liu ${ }^{1,2,3 *}$, Wenqing Shi ${ }^{1,3}$, and Qiuwen Chen ${ }^{1,3}$

\title{
Nitrogen cycles within the stream-to-riparian continuum under flood waves
}

\author{
${ }^{1}$ State Key Laboratory of Hydrology-Water Resources \& Hydraulic Engineering, Nanjing Hydraulic Research Institute, Nanjing 210029, China \\ ${ }^{2}$ College of Water Conservancy and Hydropower Engineering, Hohai University, Nanjing 210098, China \\ ${ }^{3}$ Center for Eco-Environmental Research, Nanjing Hydraulic Research Institute, Nanjing 210098, China; *Corresponding author, \\ E-mail:dsliu@nhri.cn \\ ${ }^{4}$ School of River and Ocean Engineering, Chongqing Jiaotong University, Chongqing 400074, China
}

(Received: September 19, 2019; Revised accepted: November 11, 2019)

https://doi.org/10.18814/epiiugs/2019/019027

By using a 2D-coupled flow and solute transport and reaction model across the stream-to-riparian continuum, this paper systematically studied the nitrogen-cycling processes driven by a flood wave and their spatial-temporal distributions. The influences on hyporheic nitrogen removal of different waves that vary by amplitude (A), duration $(T)$, wave-type parameter $(r)$ and rising duration $\left(t_{p}\right)$ were investigated. During the surface-water-infiltration period, the aerobic respiration, nitrification and denitrification in the hyporheic zone were gradually enhanced, and aerobic respiration was dominant. During the groundwaterbackflow period, the reactions gradually weakened, and the role of denitrification was improved. The consumption of each solute continuously increased in the whole process, and the groundwater-backflow period corresponded to a larger consumption but at a smaller consumption rate. The reaction rates in space from high to low were as follows: riparian phreatic zone $>$ variable saturated zone $>$ stream bed. Hyporheic nitrogen removal increased with increasing $A$, $T$ and $t_{p}$ and with decreasing $r$, which was contrary to the change rule of nitrogen removal efficiency. The hyporheic nitrogen removal exhibited a good linear relationship with the polynomial ' $A * T^{*} t_{p} / r$ ', which had great predictive significance.

\section{Introduction}

The rapid fluctuations and lateral spreads of flood events greatly change the hydrological regime within the stream-floodplain system (Sawyer et al., 2009; Gerecht et al., 2011; Liu et al., 2018) and affect the hydrochemical indexes in the hyporheic zone (HZ) (Curry et al., 1994; Arntzen et al., 2006; Hanrahan, 2008; Jeon and Lee, 2015). The effect of a flood event on hydrochemical indexes is through the following two ways. (1) The solutes are carried into the HZ during the surface water infiltration, or the $\mathrm{HZ}$ behaves as a source of solutes during the groundwater discharging. (2) The solutes in the HZ undergo a series of chemical reactions that change the corresponding hydrochemical indexes.

Current studies on the hydrochemical reactions in the $\mathrm{HZ}$ under flood events focus on the nitrogen cycles. In the processes of hyporheic exchange and nitrogen cycles, surface water is usually rich in dissolved oxygen (i.e., $\mathrm{O}_{2}$ ), dissolved organic carbon (DOC) and nutrients, whereas these contents in groundwater are generally lower (Dahm et al., 1998). Therefore, when surface water level rises and recharges groundwater, it carries much of $\mathrm{O}_{2}$ into the HZ. In aerobic environment, $\mathrm{NH}_{4}{ }^{+}$is converted into $\mathrm{NO}_{3}^{-}$by the action of nitrobacteria (i.e., nitrification), which contributes to the $\mathrm{NO}_{3}^{-}$source of the aquifer. Simultaneously, $\mathrm{O}_{2}$ and DOC also undergo aerobic respiration, thereby promoting the degradation of organic matter. When surface water level falls, heterotrophic microorganisms in the HZ preferentially use $\mathrm{NO}_{3}{ }^{-}$as an electron acceptor in the absence of oxygen to promote their metabolism and convert $\mathrm{NO}_{3}{ }^{-}$to $\mathrm{N}_{2}$ and $\mathrm{N}_{2} \mathrm{O}$ (i.e., denitrification). According to Böhlke and Denver (1995) and Marzadri et al. (2011), the threshold concentration of $\mathrm{O}_{2}$ for denitrification in stream sediment is $3 \mathrm{mg} / \mathrm{l}$, assuming $\mathrm{NO}_{3}{ }^{-}$is completely reduced to $\mathrm{N}_{2}$.

Scholars have conducted a lot of researches on the hyporheic nitrogen cycles under flood events through field tracer tests. For example, Stanley and Boulton (1995) studied the nitrogen cycles in streamfloodplain system under alternating wet and dry processes, indicating that the concentrations of nitrates and dissolved oxygen drop sharply during flood attenuation. Moreover, with weakening hyporheic exchange, the $\mathrm{HZ}$ reaches an extremely hypoxic state $\left(\mathrm{O}_{2}\right.$ concentration $\left.<0.5 \mathrm{mg} / \mathrm{L}\right)$, and the nitrate nitrogen concentration is also at a lower level $(<0.02 \mathrm{mg} / \mathrm{L})$, after which denitrification dominates. Roley et al. (2012) conducted an in situ measurement and analysis of the nitrate concentration and nitrification rate in the HZ under flood events in Shatto Creek, USA. The authors' results showed that nitrification rate in the floodplain area gradually increases with the expansion of flood-submerged area and has different performances in the process of flood rise-peak-fall. Harvey et al. (2013) investigated denitrification in the HZ by injecting ${ }^{15} \mathrm{NO}_{3}{ }_{3}^{-}$in the upstream of Sugar Creek, USA, and the HZ plays a dominant role in the denitrification process of the river system. Moreover, the denitrification rate is proportional to the magnitude of hyporheic exchange. 
At present, researches on the mechanism of hyporheic nitrogen cycles focus on topographic factors and rely on numerical simulation. For example, Bardini et al. (2012) simulated the nitrogen cycles in the $\mathrm{HZ}$ driven by streambed dunes under steady flow conditions. The authors found that the availability of DOC determines whether the stream bed is the source or sink of nitrate. Bardini et al. (2013) further clarified that sediment heterogeneity has minimal effect on stream bed nutrient dynamics compared with stream bed morphology. Hu et al. (2014) emphasized that ignoring the micro-morphology in the large stream bed structure will underestimate the discharge of nitrate nitrogen from the HZ to the stream. Gu et al. (2007) studied the effects of flow and biogeochemical conditions on nitrate reduction in stream bed through indoor flume test and numerical simulation. They found that nitrate concentration of groundwater drainage is controlled by groundwater discharge rate and by the rates of aerobic respiration and denitrification.

However, studies on the mechanism of hyporheic nitrogen cycles driven by flood events are lacking. Gu et al. (2012) was the first to simulate the effects of flood waves on hyporheic exchange and nitrogen cycles. The lateral exchange in the riparian zone greatly improves the efficiency of hyporheic nitrogen removal. Furthermore, they revealed positive correlations between nitrogen removal and wave amplitude, duration, bank storage and maximum solute storage. However, their model did not consider nitrification, which might play a lead role in short hyporheic exchange paths and hydrological retention time (Zarnetske et al., 2011). Shuai et al. (2017) built an improved flow-solute transport model and explored the effects of surface-groundwater hydraulic gradient, aquifer hydraulic conductivity and dispersivity on hyporheic nitrogen removal under flood waves. The study's results indicated that when surface water is in gaining condition, large aquifer hydraulic conductivity and dispersivity lead to great hyporheic nitrogen removal and efficiency. Similarly, Trauth et al. (2018) revealed that aerobic respiration and denitrification efficiency in the $\mathrm{HZ}$ increase correspondingly with the increase of amplitude and duration of flood wave through numerical simulations.

In summary, the understanding of mechanism of hyporheic nitrogen cycles driven by flood waves is unclear. Understanding of spatialtemporal distribution of hydrochemical characteristic quantities in a stream bed, riparian phreatic zone and variable saturated zone is lacking. Moreover, although previous studies fully discussed the influence of wave amplitude and duration on nitrogen cycles, the parameters characterizing the roundness and skewness of a wave remain unexamined. Hence, this study aims to solve the following three problems: (1) revealing the dynamics of reaction rates, solute consumption and consumption rates of hyporheic nitrogen cycles in response to a flood wave; (2) illustrating the variations of solute concentrations, solute plumes and reaction rates in stream-to-riparian continuum; and (3) systematically exploring the influence of four typical wave parameters on hyporheic nitrogen removal.

\section{Methods}

\section{Site and Model Descriptions}

This study adopted the field test and flow model from Liu et al. (2019), based on which the solute transport and reaction model were coupled. The field site $\left(128^{\circ} 12^{\prime} 18^{\prime \prime} \mathrm{E}, 38^{\circ} 13^{\prime} 15^{\prime \prime} \mathrm{N}\right)$ is located in the upstream of the Inbuk stream, Korea, where the stream stage amplitude and duration are able to reach $1 \mathrm{~m}$ and 5 days respectively due to seasonal flooding. Several piezometers were installed across the stream-to-riparian continuum at intervals of $10 \mathrm{~m}$ for evaluating the hyporheic exchange between surface water and groundwater. And some chemical indexes in the surface water and groundwater were also measured.

\section{Governing Equations}

The model coupled Richard's Equation (Voss, 1984) and convection-dispersion-reaction Equation (1), as follows:

$$
\frac{\partial}{\partial t}\left(\theta C_{j}\right)-\nabla \cdot\left(\theta \boldsymbol{D} \nabla C_{j}\right)+\nabla \cdot\left(\boldsymbol{q} C_{j}\right)=R_{j}
$$

where $\theta$ is the water content, $C_{j}$ is the concentration of solute $j, \boldsymbol{D}$ is the hydrodynamic dispersivity tensor, $\boldsymbol{q}$ is the Darcy velocity vector, $R_{j}$ is the reaction rate of solute $j$ and $t$ is the time.

The nitrogen-cycling processes involved in this model included aerobic respiration, nitrification and denitrification. DOC was represented by the chemical formula ' $\mathrm{CH}_{2} \mathrm{O}$ ', and all the reaction equations were as follows:

$$
\begin{aligned}
& \mathrm{CH}_{2} \mathrm{O}+\mathrm{O}_{2} \rightarrow \mathrm{H}_{2} \mathrm{O}+\mathrm{CO}_{2} \\
& \mathrm{NH}_{4}^{+}+2 \mathrm{O}_{2} \rightarrow \mathrm{NO}_{3}^{-}+\mathrm{H}_{2} \mathrm{O}+2 \mathrm{H}^{+} \\
& 5 \mathrm{CH}_{2} \mathrm{O}+4 \mathrm{NO}_{3}^{-}+4 \mathrm{H}^{+} \rightarrow 7 \mathrm{H}_{2} \mathrm{O}+5 \mathrm{CO}_{2}+2 \mathrm{~N}_{2}
\end{aligned}
$$

The Multiple-Monod kinetics model was used to characterize the aforementioned nitrogen-cycling processes (Molz et al., 1986). $R_{j}$ in Equation (1) was expressed by the following formula:

$$
\begin{gathered}
R_{O 2}=-\theta V_{A R} X_{A R} y_{O 2}\left(\frac{C_{D O C}}{K_{D O C}+C_{D O C}}\right)\left(\frac{C_{O 2}}{K_{O 2}+C_{O 2}}\right) \\
-\theta V_{N T} X_{N T}\left(1-y_{O 2}\right)\left(\frac{C_{N H 4}}{K_{N H 4}+C_{N H 4}}\right)\left(\frac{C_{O 2}}{K_{O 2}+C_{O 2}}\right) \\
R_{N H 4}=-\theta V_{N T} X_{N T}\left(\frac{C_{N H 4}}{K_{N H 4}+C_{N H 4}}\right)\left(\frac{C_{O 2}}{K_{O 2}+C_{O 2}}\right) \\
R_{N O 3}=\theta V_{N T} X_{N T}\left(\frac{C_{N H 4}}{K_{N H 4}+C_{N H 4}}\right)\left(\frac{C_{O 2}}{K_{O 2}+C_{O 2}}\right) \\
-\theta V_{D N} X_{D N}\left(\frac{K_{I}}{K_{I}+C_{O 2}}\right)\left(\frac{C_{D O C}}{K_{D O C}+C_{D O C}}\right)\left(\frac{C_{N O 3}}{K_{N O 3}+C_{N O 3}}\right) \\
R_{D O C}=-\theta V_{A R} X_{A R} y_{O 2}\left(\frac{C_{D O C}}{K_{D O C}+C_{D O C}}\right)\left(\frac{C_{O 2}}{K_{O 2}+C_{O 2}}\right) \\
-\theta V_{D N} X_{D N}\left(\frac{K_{I}}{K_{I}+C_{O 2}}\right)\left(\frac{C_{D O C}}{K_{D O C}+C_{D O C}}\right)\left(\frac{C_{N O 3}}{K_{N O 3}+C_{N O 3}}\right)
\end{gathered}
$$

where $C_{\mathrm{O} 2}, C_{\mathrm{NH} 4}, C_{\mathrm{NO} 3}$ and $C_{\mathrm{DOC}}$ are the concentrations of $\mathrm{O}_{2}, \mathrm{NH}_{4}^{+}$, $\mathrm{NO}_{3}{ }_{3}$ and DOC, respectively; $R_{\mathrm{O} 2}, R_{\mathrm{NH} 4}, R_{\mathrm{NO} 3}$ and $R_{\mathrm{DOC}}$ are the reaction rates for $\mathrm{O}_{2}, \mathrm{NH}_{4}{ }^{+}, \mathrm{NO}_{3}{ }^{-}$and DOC, respectively; $V_{\mathrm{AR}}, V_{\mathrm{NT}}$ and $V_{\mathrm{DN}}$ are the maximum specific uptake rates of the substrate for aerobic respiration (AR), nitrification (NT) and denitrification (DN), respectively; $X_{\mathrm{AR}}, X_{\mathrm{NT}}$ and $X_{\mathrm{DN}}$ are the biomass of the functional microbial group facilitating the different reaction components for AR, NT and DN, respectively; $K_{\mathrm{O} 2}, K_{\mathrm{NH} 4}, K_{\mathrm{NO} 3}$ and $K_{\mathrm{DOC}}$ are the half-saturation con- 
stants for $\mathrm{O}_{2}, \mathrm{NH}_{4}^{+}, \mathrm{NO}_{3}{ }^{-}$and DOC, respectively; $K_{\mathrm{I}}$ is an inhibition constant; $y_{\mathrm{O} 2}$ is the $\mathrm{O}_{2}$ partition coefficient; and $U_{\mathrm{AR}}, U_{\mathrm{NT}}$ and $U_{\mathrm{DN}}(U$ $=V X)$ are the lumped specific maximum microbial reaction rates for $\mathrm{AR}, \mathrm{NT}$ and DN, respectively.

\section{Boundary Conditions and Input Parameters}

The concentrations for $\mathrm{O}_{2}, \mathrm{NO}_{3}{ }^{-}$and $\mathrm{NH}_{4}{ }^{+}$on the stream-aquifer boundary were set based on measured values of 5,5 and $0.05 \mathrm{mg} / \mathrm{L}$, respectively (Fig. 1). It was also set to $5 \mathrm{mg} / \mathrm{L}$ for DOC to compare better the degree of reaction of each solute owing to the lack of DOC concentration in surface water. Moreover, a conservative solute boundary condition $\left(\mathrm{Na}^{+}\right)$was also set, which was completely consistent with that of $\mathrm{NO}_{3}$. The initial values of all solutes in the model were set to zero and were uniformly distributed. The longitudinal and transverse dispersivity of the model were set to 0.1 and $0.01 \mathrm{~m}$, respectively, according to the model scale and the empirical values. Other biochemical parameters were also determined by basing on the empirical values of previous similar studies (Table 1).

\section{Quantifications of Nitrogen Cycles}

For multi-component reactive solutes $\left(\mathrm{O}_{2}, \mathrm{NH}_{4}{ }^{+}, \mathrm{NO}_{3}{ }^{-}\right.$and DOC), the consumption of solute $j\left(M_{\mathrm{rem}-j}\right)$ at any time during water-level fluctuation was obtained by the following:

$$
M_{\mathrm{rem}-j}=\int_{0}^{T} \int_{\Omega} \theta R_{j} d \Omega d t
$$

where $T$ is the total simulation time and $\Omega$ is the study area.

The consumption rate $\left(R_{\mathrm{rem}-j}\right)$ of solute $j$ was obtained by deriving $M_{\text {rem-j }}$ with respect to $t$ :

$$
R_{\mathrm{rem}-j}=\frac{d M_{\mathrm{rem}-j}}{d t}
$$

The consumption efficiency $\left(N_{\mathrm{rem}-j}\right)$ of solute $j$ was further determined by the following:

$$
N_{\mathrm{rem}-j}=\frac{M_{\mathrm{rem}-j}}{M_{\mathrm{in}-j}}
$$

where $M_{\mathrm{in}-j}$ is the maximum storage of solute $j$ in the aquifer:

$$
M_{\mathrm{in}-j}=\int_{0}^{t_{F}} C_{0} q(t) d t
$$

where $C_{0}$ is the initial concentration of surface water, $t_{\mathrm{F}}$ is the surface water infiltration time and $q$ denotes the exchange flux between the surface water and groundwater, which is obtained by integrating the normal velocity $\left(v_{n}\right)$ along the stream-aquifer interface:

$$
q=\int_{0}^{l} v_{n} d l
$$

where $l$ is the length of the stream-aquifer interface.

In addition, the average reaction rate $\left(\bar{R}_{J}\right)$ of solute $j$ within the study domain was further determined by the following:

$$
\bar{R}_{J}=\frac{d\left[M_{\mathrm{rem}-j} / Q(t)\right]}{d t}
$$

where $Q(t)$ is the aquifer storage, which is obtained by integrating the $q$ mentioned above over time.

$$
Q(t)=\int_{0}^{t} q d t
$$

\section{Model Scenarios}

As Inbuk Stream is subjected to seasonal flooding and reservoir drainage throughout the year, the surface water level exhibits approximately sinusoidal fluctuation (Liu et al., 2019), as follows:

$$
h(t)=h_{0}+A \sin ^{r}\left[\left(\frac{t}{R}\right)^{-\ln 2 / \ln \left(\frac{t_{p}}{T}\right)} \pi\right]
$$

where $h_{0}$ is the elevation of stream bottom, $A$ is the amplitude characterizing the height of a flood wave, $T$ is the duration characterizing the width of a flood wave, $r$ is the wave type parameter characterizing the roundness of a flood wave, and $t_{\mathrm{p}}$ is the rising duration characterizing the skewness of a flood wave.

The range of each parameter was roughly determined based on the measured stream water level data from 2014 to 2016, and a variety of waveforms of different $A, T, r$ and $t_{\mathrm{p}}$ were generalized (Fig. 2).

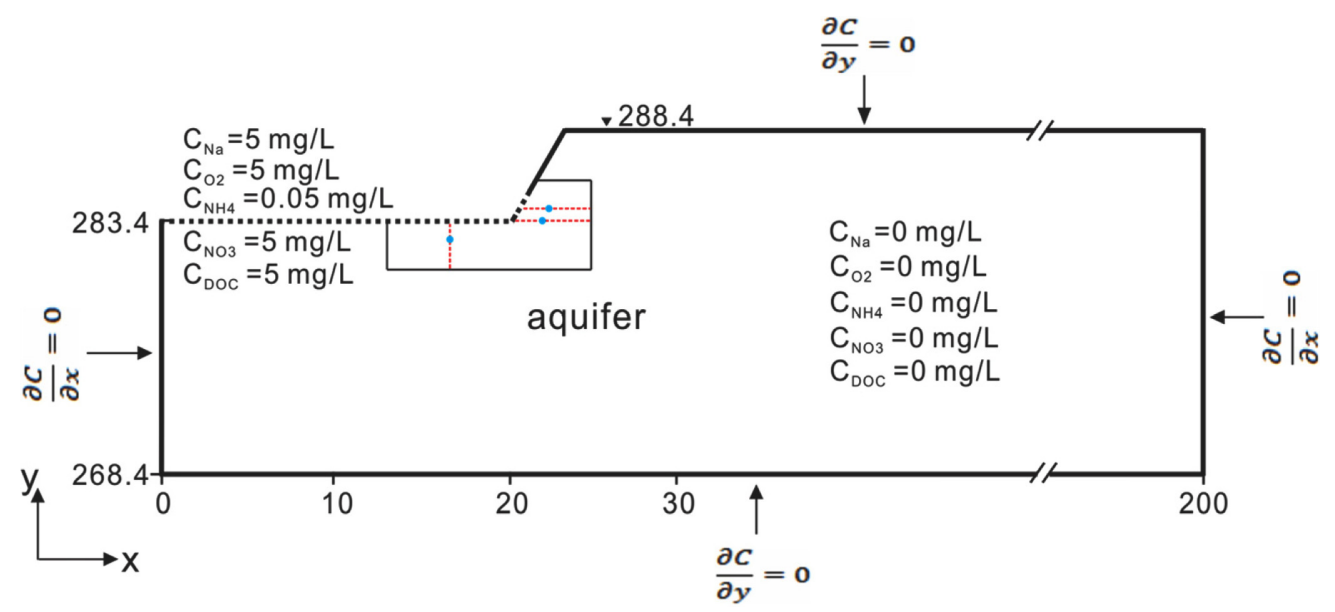

Figure 1. Conceptual flow-transport-reaction coupling model across the stream-to-riparian continuum. The dotted boundary denotes the submerged area. The blue points denote the observation points in stream bed, riparian phreatic zone and riparian variable saturated zone with the same distance from the stream-aquifer interface. 
Table 1. Input parameters of flow-transport-reaction coupling model

\begin{tabular}{|c|c|c|}
\hline Parameters & Values & Units \\
\hline \multicolumn{3}{|l|}{ Hydrodynamic Model Parameters } \\
\hline Saturated hydraulic conductivity $(K)^{(\mathrm{a})}$ & 3.47E-5 & {$[\mathrm{m} / \mathrm{s}]$} \\
\hline Effective porosity $\left(n_{\mathrm{e}}\right)^{(\mathrm{a})}$ & 0.41 & {$[-]$} \\
\hline Specific storage $\left(S_{0}\right)^{(\mathrm{a})}$ & 0.0001 & {$[1 / \mathrm{m}]$} \\
\hline Residual saturation $\left(s_{\mathrm{r}}\right)^{(\text {a) }}$ & 0.146 & {$[-]$} \\
\hline Maximum saturation $\left(S_{\mathrm{s}}\right)^{(\mathrm{a})}$ & 0.96 & {$[-]$} \\
\hline van Genuchten parameter $(\xi)^{(a)}$ & 7.5 & {$[1 / \mathrm{m}]$} \\
\hline van Genuchten parameter $(n)^{(\mathrm{a})}$ & 1.95 & {$[-]$} \\
\hline Longitudinal dispersivity $\left(D_{\mathrm{L}}\right)^{(\mathrm{b})}$ & 0.1 & {$[\mathrm{~m}]$} \\
\hline Longitudinal/Transverse dispersivity ratio $\left(D_{\mathrm{L}} / D_{\mathrm{T}}\right)^{(\mathrm{b})}$ & 0.01 & {$[-]$} \\
\hline \multicolumn{3}{|l|}{ Water Quality Model Parameters } \\
\hline $\mathrm{O}_{2}$ concentration in surface water ${ }^{(\mathrm{c})}$ & 5 & {$[\mathrm{mg} / \mathrm{L}]$} \\
\hline $\mathrm{NH}_{4}^{+}$concentration in surface water ${ }^{(\mathrm{c})}$ & 0.05 & {$[\mathrm{mg} / \mathrm{L}]$} \\
\hline $\mathrm{NO}_{3}$ concentration in surface water ${ }^{(\mathrm{c})}$ & 5 & {$[\mathrm{mg} / \mathrm{L}]$} \\
\hline DOC concentration in surface water ${ }^{(c)}$ & 5 & {$[\mathrm{mg} / \mathrm{L}]$} \\
\hline $\mathrm{Na}^{+}$concentration in surface water ${ }^{(\mathrm{c})}$ & 5 & {$[\mathrm{mg} / \mathrm{L}]$} \\
\hline $\mathrm{O}_{2}, \mathrm{NH}_{4}^{+}, \mathrm{NO}_{3}^{-}, \mathrm{DOC}, \mathrm{Na}^{+}$concentration in the aquifer and recharge water ${ }^{(\mathrm{c})}$ & 0 & {$[\mathrm{mg} / \mathrm{L}]$} \\
\hline Maximum specific uptake rate for $\mathrm{AR}\left(U_{\mathrm{AR}}\right)^{(\mathrm{d}, \mathrm{e}, \mathrm{f})}$ & 2 & {$[\mathrm{mg} / \mathrm{L} / \mathrm{d}]$} \\
\hline Maximum specific uptake rate for $\mathrm{NI}\left(U_{\mathrm{NI}}\right)^{(\mathrm{d})}$ & 1.05 & {$[\mathrm{mg} / \mathrm{L} / \mathrm{d}]$} \\
\hline Maximum specific uptake rate for DN $\left(U_{\mathrm{DN}}\right)^{(\mathrm{d}, \mathrm{e}, \mathrm{f})}$ & 2 & {$[\mathrm{mg} / \mathrm{L} / \mathrm{d}]$} \\
\hline Half saturation constant for $\mathrm{O}_{2}\left(K_{\mathrm{O} 2}\right)^{(\mathrm{d}, \mathrm{e}, \mathrm{f})}$ & 1 & {$[\mathrm{mg} / \mathrm{L}]$} \\
\hline Half saturation constant for $\mathrm{NH}_{4}^{+}\left(K_{\mathrm{NH} 4}\right)^{(\mathrm{d}, \mathrm{e})}$ & 0.5 & {$[\mathrm{mg} / \mathrm{L}]$} \\
\hline Half saturation constant for $\mathrm{NO}_{3}^{-}\left(K_{\mathrm{NO} 3}\right)^{(\mathrm{d}, \mathrm{e}, \mathrm{f})}$ & 1 & {$[\mathrm{mg} / \mathrm{L}]$} \\
\hline Half saturation constant for DOC $\left(K_{\mathrm{DOC}}\right)^{(\mathrm{d}, \mathrm{e}, \mathrm{f})}$ & 5 & {$[\mathrm{mg} / \mathrm{L}]$} \\
\hline $\mathrm{O}_{2}$ inhibition constant $\left(K_{\mathrm{I}}\right)^{(\mathrm{d}, \mathrm{e})}$ & 1 & {$[\mathrm{mg} / \mathrm{L}]$} \\
\hline $\mathrm{O}_{2}$ partition coefficient $\left(y_{\mathrm{O} 2}\right)^{(\mathrm{d})}$ & 0.64 & {$[-]$} \\
\hline
\end{tabular}

(a) Identified parameters of flow model (Liu et al., 2019).

(b) Literature empirical values (Fetter, 2000; Gelharet et al., 1992; Neuman, 1990; Schulze-Makuch, 2005).

${ }^{(c)}$ Measured values.

${ }^{(d)}$ Literature empirical values (Zarnetske et al., 2012).

${ }^{(e)}$ Literature empirical values (Lee et al., 2006; Shuai et al., 2017; Gu et al., 2012; Hu et al., 2014).

${ }^{(\mathrm{f})}$ Literature empirical values (Gu et al., 2007).

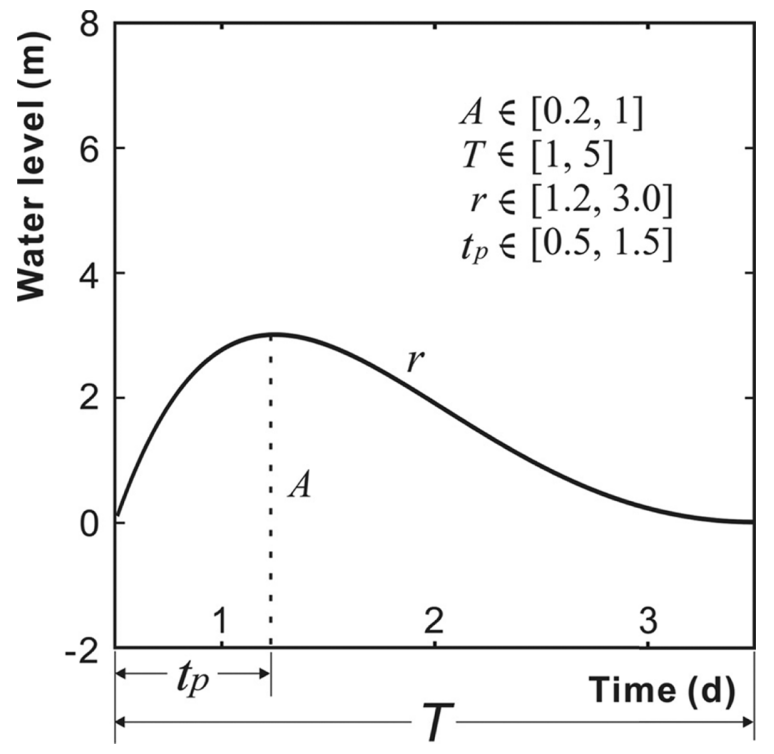

Figure 2. Schematic diagram of a flood wave.

\section{Results}

\section{Dynamics of Solute Transformations in Response to a Flood Wave}

Fig. 3 showed the dynamics of average reaction rates, solute consumption and consumption rates in response to hyporheic exchange flux. The processes were roughly divided into three periods. (1) Surface-water-infiltration period $(0.5<t<2.35 \mathrm{~d})$. The average reaction rate of each solute gradually increased (Fig. $3 b$ ), and the consumption and consumption rate increased accordingly (Fig. 3c, d), but their trends gradually slowed down in the latter half. (2) Groundwater-backflow period with the intensity gradually approaching the maximum value $(2.35<t<3.1 \mathrm{~d})$. As the solute concentrations decreased, the average reaction rate and consumption rate dropped sharply (especially of DOC and $\mathrm{O}_{2}$ ), and the increasing trend of solute consumption slowed down. (3) Groundwater-backflow period with the intensity gradually approaching zero $(t>3.1 \mathrm{~d})$. Solute concentration in the HZ gradually 

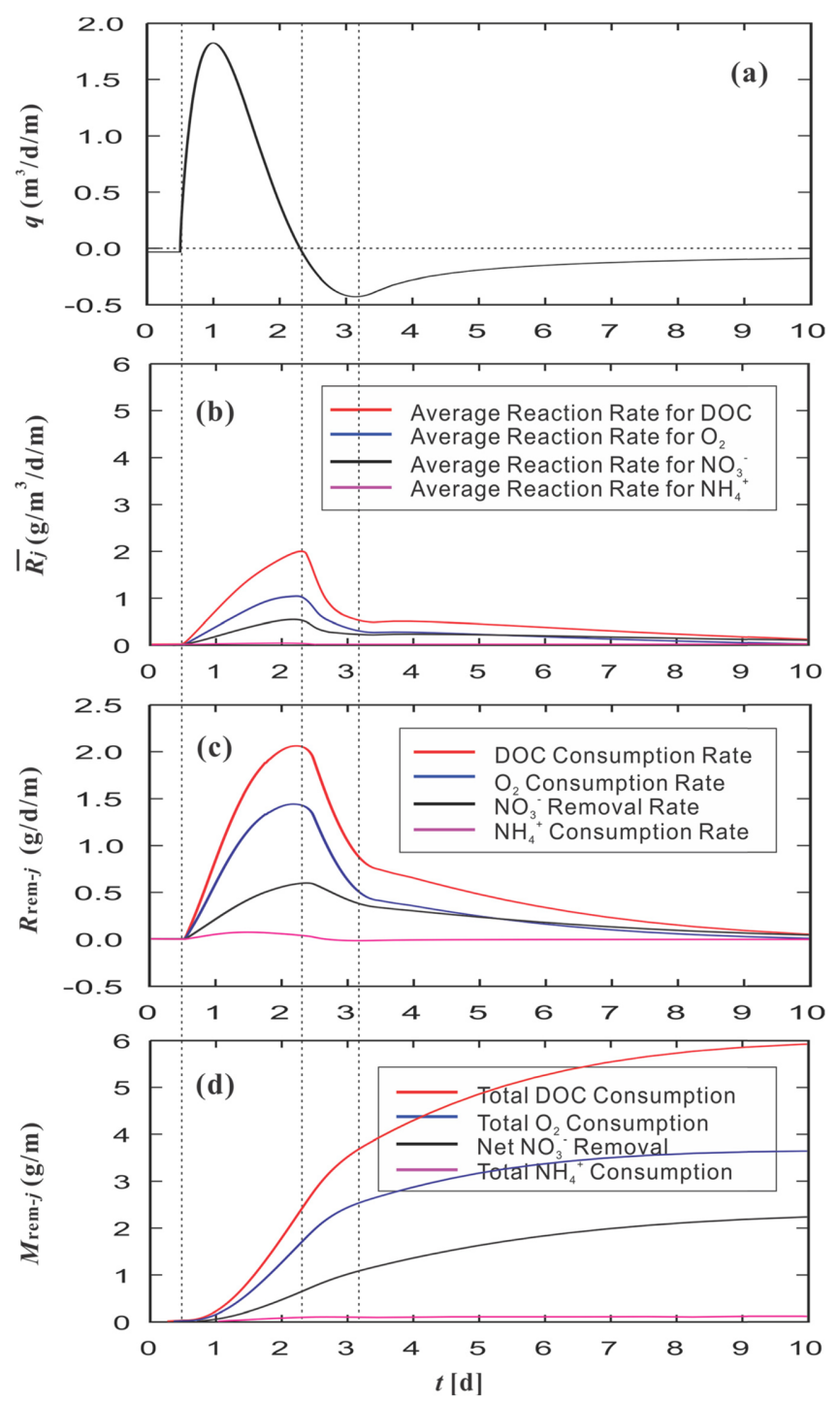

Figure 3. Change processes of surface water-groundwater exchange flux (a), average solute reaction rates (b), consumption rates (c) and consumption (d) within the study domain.

approached the initial value, and the average reaction rate and consumption rate decreased with slow trends. By contrast, the solute consumption continued to increase in a very gradual trend.

\section{Spatial-temporal Features of Nitrogen Cycles Driven by a Flood Wave}

Fig. 4 showed the distributions of hydraulic head and solute concentrations $\left(\mathrm{O}_{2}, \mathrm{NH}_{4}^{+}, \mathrm{NO}_{3}^{-}\right.$, DOC and $\left.\mathrm{Na}^{+}\right)$across the stream-to-riparian continuum at typical moments of a flood wave (base case). During the rising limb $(0.5<t<1.25 \mathrm{~d}), \mathrm{O}_{2}, \mathrm{NO}_{3}^{-}$, DOC and $\mathrm{Na}^{+}$solute plumes were constantly expanding, whereas the range of $\mathrm{NH}_{4}{ }^{+}$plume changed slightly due to the lower actual concentration. During the falling limb before $t$ $=2 \mathrm{~d}, \mathrm{O}_{2}, \mathrm{NO}_{3}{ }_{3}, \mathrm{DOC}$ and $\mathrm{Na}^{+}$plumes were still expanding, but the $\mathrm{NH}_{4}^{+}$plume shrank considerably. As the surface water level continued to fall (e.g., $t=2.5 \mathrm{~d}$ ), groundwater switched to recharge surface water. Hence, $\mathrm{O}_{2}, \mathrm{NO}_{3}^{-}$, DOC and $\mathrm{Na}^{+}$plumes no longer expanded, and $\mathrm{NH}_{4}^{+}$was almost completely oxidized by $\mathrm{O}_{2}$. At the end of the flood (i.e., $t=3.5 \mathrm{~d}$ ), the plumes of $\mathrm{O}_{2}$ and DOC begin to be markedly smaller than that of $\mathrm{NO}_{3}^{-}$, while the $\mathrm{NO}_{3}^{-}$plume is slightly smaller than that of $\mathrm{Na}^{+}$. In the next long flood recession period $(3.5<t<20 \mathrm{~d})$, all the solute plumes were constantly shrinking at different speeds: DOC $>\mathrm{O}_{2}>\mathrm{NO}_{3}^{-}>\mathrm{Na}^{+}$. Although $\mathrm{NO}_{3}^{-}$consumed slowly in the whole process, it consumed relatively fast in the recession period.

The shape of the solute plume in the stream-to-riparian continuum was similar to the envelope surface of tracer particles (Chen et al., 2003), which meant that in the vertical direction, the closer to the stream centre, the more shallowly the solute was transported. By comparison, in the lateral direction, the closer to the initial groundwater level, the more widely the solute was transported. To compare the nitrogen-cycling processes for different areas (stream bed, riparian phreatic zone and riparian variable saturated zone), observation points were set in each area. Fig. 5a-d showed that during the surface-water-infiltration period, the concentration for each solute in the riparian phreatic and riparian variable saturated zones almost increased in the same way. The increase in magnitude and speed were larger than that in the streambed. Similar variation trends were found for reaction rate of each chemical process (Fig. 5e-g). During the groundwater-backflow period, the decline rate of concentration in space from high to low was as follows: riparian phreatic zone $>$ variable saturated zone $>$ stream bed. However, the decline of reaction rate in space from high to low was as follows: variable saturated zone $>$ riparian phreatic zone $>$ stream bed.

\section{Hyporheic Nitrogen Removal under Different Flood Waves}

Table 2 showed the variations of $M_{\text {in- } \mathrm{NO} 3}, M_{\text {rem-NO3 }}$ and $N_{\text {rem-NO3 }}$ under different flood waves. The trends of $M_{\text {rem-NO3 }}$ and $M_{\text {in-NO3 }}$ were almost the same, which were positively correlated with $A, T$ and $t_{\mathrm{p}}$, but negatively correlated with $r$. However, $N_{\text {rem-NO3 }}$ showed the opposite trend with $M_{\text {rem-NO3 }}$ or $M_{\text {in-NO3 }}$. Fig. 6 showed the fitting relationship between $M_{\text {rem-NO3 }}$ and the polynomial ' $A * T^{*} t_{\mathrm{p}} / r$ ' with the correlation coefficient being $R^{2}=0.82$, which suggested a good correlation.

\section{Discussion}

\section{Mechanism of Flood-wave-driven Solute Transformations}

During the surface-water-infiltration period, the solute consumption and consumption rate increased with increasing solute reaction rate (Fig. 3b-d), but their trends gradually slowed down in the latter half. This trend arose because the intensity of recharge from surface water to aquifer gradually decreased (Fig. 3a), resulting in a slower rise in solute concentration, which was an important indicator affecting chemical reaction. Thus, with increasing concentration of each solute during the surface-water-infiltration period, the corresponding chemical reactions were strengthened, especially aerobic respiration. Although the reaction rate of $\mathrm{NO}_{3}{ }^{-}$increased during this period, the magnitude was relatively small due to the inhibition of rich $\mathrm{O}_{2}$. During the groundwater-backflow period, the reaction rates for DOC and $\mathrm{O}_{2}$ decreased significantly, whereas the reaction rate of $\mathrm{NO}_{3}^{-}$decreased minimally. These findings indicated that with decreasing $\mathrm{O}_{2}$ concentration, its inhibition decreased, and the role of denitrification improved. From Fig. 3d, the consumption of each solute was constantly increasing 


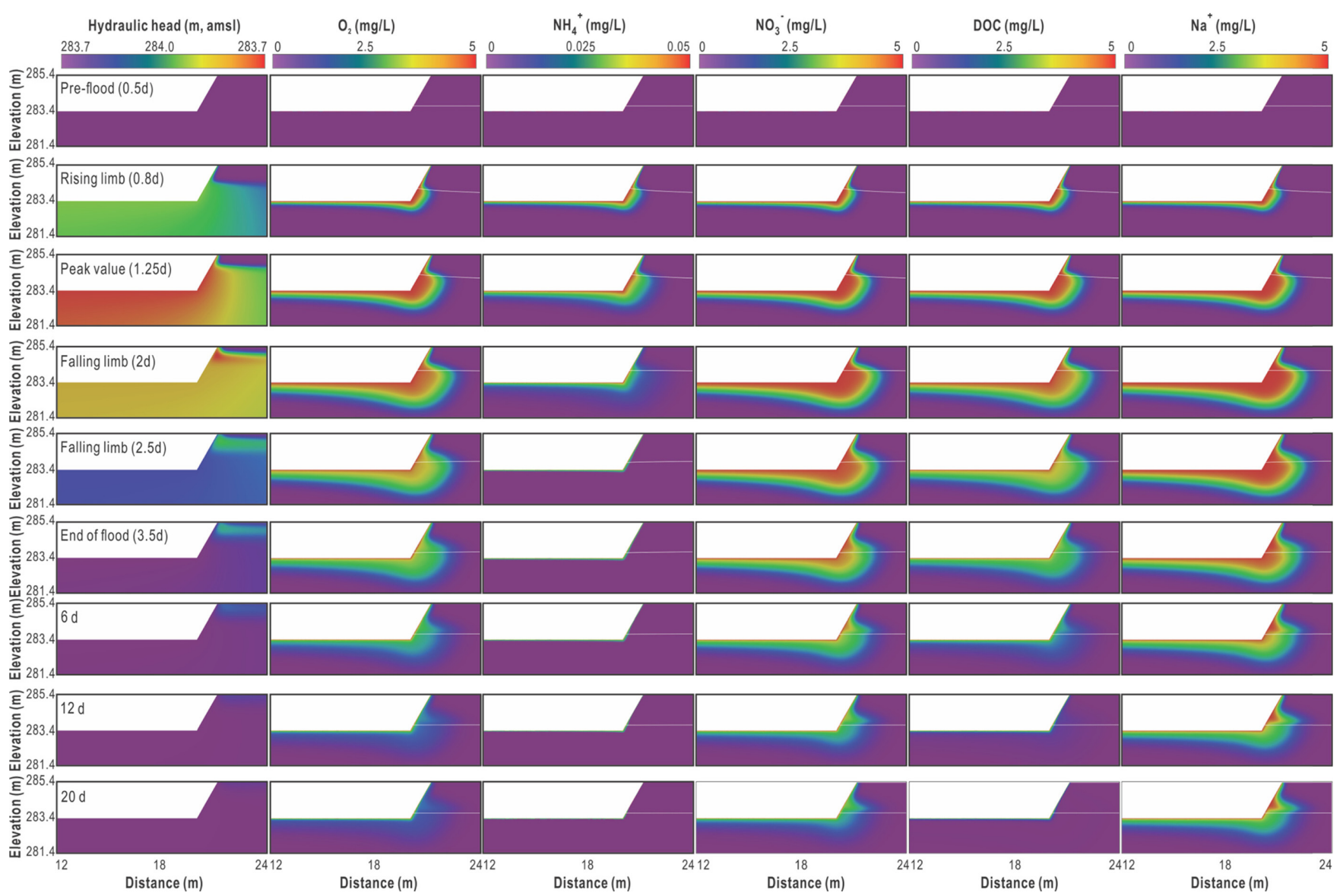

Figure 4. Distributions of hydraulic head and solute concentrations across the stream-to-riparian continuum at typical moments of a flood wave.

Table 2. $\mathrm{NO}_{3}^{-}$maximum storage $\left(\mathrm{M}_{\mathrm{in}-\mathrm{NO}}\right), \mathrm{NO}_{3}^{-}$removal $\left(\mathrm{M}_{\text {rem-No3 }}\right)$ and $\mathrm{NO}_{3}^{-}$removal efficiency $\left(\mathrm{N}_{\text {rem-No3 }}\right)$ under different water waves

\begin{tabular}{|c|c|c|c|c|c|}
\hline & Parameters & Conditions & 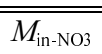 & 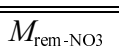 & $N_{\text {rem-NO3 }}$ \\
\hline \multirow{20}{*}{$\begin{array}{l}\text { Different flood wave } \\
\text { parameters }\end{array}$} & \multirow{5}{*}{$\begin{array}{c}\text { Amplitude, } A \\
\left(T=3, r=2.0, t_{\mathrm{p}}=T / 4\right)\end{array}$} & 0.2 & 4.744 & 1.034 & $21.80 \%$ \\
\hline & & 0.4 & 8.534 & 1.698 & $19.90 \%$ \\
\hline & & 0.6 & 12.244 & 2.321 & $18.96 \%$ \\
\hline & & 0.8 & 15.953 & 2.937 & $18.41 \%$ \\
\hline & & 1.0 & 19.707 & 3.548 & $18.00 \%$ \\
\hline & \multirow{5}{*}{$\begin{array}{c}\text { Duration, } T \\
\left(A=0.6, r=2.0, t_{\mathrm{p}}=T / 4\right)\end{array}$} & 1 & 6.520 & 1.372 & $21.04 \%$ \\
\hline & & 2 & 9.724 & 1.886 & $19.40 \%$ \\
\hline & & 3 & 12.244 & 2.321 & $18.96 \%$ \\
\hline & & 4 & 14.428 & 2.693 & $18.67 \%$ \\
\hline & & 5 & 16.364 & 3.058 & $18.69 \%$ \\
\hline & \multirow{5}{*}{$\begin{array}{l}\text { Wave type parameter, } r \\
\left(A=0.6, T=3, t_{\mathrm{p}}=T / 4\right)\end{array}$} & 1.2 & 13.801 & 2.577 & $18.67 \%$ \\
\hline & & 1.5 & 13.114 & 2.463 & $18.78 \%$ \\
\hline & & 2.0 & 12.244 & 2.321 & $18.96 \%$ \\
\hline & & 2.5 & 11.495 & 2.207 & $19.20 \%$ \\
\hline & & 3.0 & 11.082 & 2.119 & $19.12 \%$ \\
\hline & \multirow{5}{*}{$\begin{array}{c}\text { Rising duration, } t_{\mathrm{p}} \\
(A=0.6, T=3, r=2.0)\end{array}$} & $T / 6=0.5$ & 11.346 & 2.172 & $19.14 \%$ \\
\hline & & $T / 5=0.6$ & 11.786 & 2.24 & $19.01 \%$ \\
\hline & & $T / 4=0.75$ & 12.244 & 2.321 & $18.96 \%$ \\
\hline & & $T / 3=1$ & 12.729 & 2.391 & $18.78 \%$ \\
\hline & & $T / 2=1.5$ & 13.071 & 2.445 & $18.71 \%$ \\
\hline
\end{tabular}

*The shaded area corresponds to the base case (i.e., $A=0.6 \mathrm{~m}, T=3 \mathrm{~d}, r=2.0$ and $t_{\mathrm{p}}=T / 4=0.75 \mathrm{~d}$ ). Different flood wave parameters are generated based on the base case by changing only one parameter at a time and keeping the remaining parameters unchanged. 
during the flood event. Each solute consumed faster when surface water infiltrated into the aquifer, while it consumed more slowly when the groundwater flowed back. However, the consumption of each solute during the surface-water-infiltration period was smaller than that during the groundwater-backflow period. This result was due to the fact that the hydrological retention time during the groundwater-backflow period was much longer than that in the surface-water-infiltration period, which provided sufficient reaction time for each chemical process.

\section{Principle of Spatiotemporal Variations of Flood-wave- driven Nitrogen Cycles}

Generally, each solute plume expanded during the rising limb of surface water level and shrank during the falling limb. However, $\mathrm{O}_{2}$, $\mathrm{NO}_{3}{ }_{3}^{-}$and DOC plumes showed expansion trends during a preceding period of the falling limb, because the aquifer was still recharged by the surface water although the surface water level declined, and the solute amount being carried into the $\mathrm{HZ}$ was much more than the reaction removal. $\mathrm{NO}_{3}$ - plume was the largest, because aerobic respiration and nitrification were strong at this period, whereas denitrification was limited by rich $\mathrm{O}_{2}$. Moreover, nitrification produced some extra $\mathrm{NO}_{3}{ }^{-}$. Although both $\mathrm{O}_{2}$ and DOC underwent aerobic respiration, less $\mathrm{O}_{2}$ participated in nitrification, whereas more DOC participated in denitrification, thereby resulting in the plume of $\mathrm{O}_{2}$ being slightly larger than that of DOC.

By comparing the variations in the concentration of $\mathrm{O}_{2}, \mathrm{NO}_{3}{ }^{-}$and DOC in three areas, we found that DOC concentration decreased the most, followed by $\mathrm{O}_{2}$ and then $\mathrm{NO}_{3}^{-}$, which indicated that aerobic respiration was dominant in the whole process. This result was supported by comparing Fig. 5(f) and (g).The oxidation rate during a flood wave was about four times than that of denitrification rate. The reason the consumption of DOC was markedly higher than that of $\mathrm{O}_{2}$ was that the denitrification rate in which DOC was involved was significantly higher than the nitrification rate that $\mathrm{O}_{2}$ was involved in, which was supported by comparing Fig. 5(e) and (g). The denitrification rate was about thrice that of the nitrification rate. In addition, the overall reaction rate of each process in stream bed was smaller than that in the riparian zone, which was due to the relatively shallow but wide aquifer, resulting in a smaller amount of solute being carried into the vertical
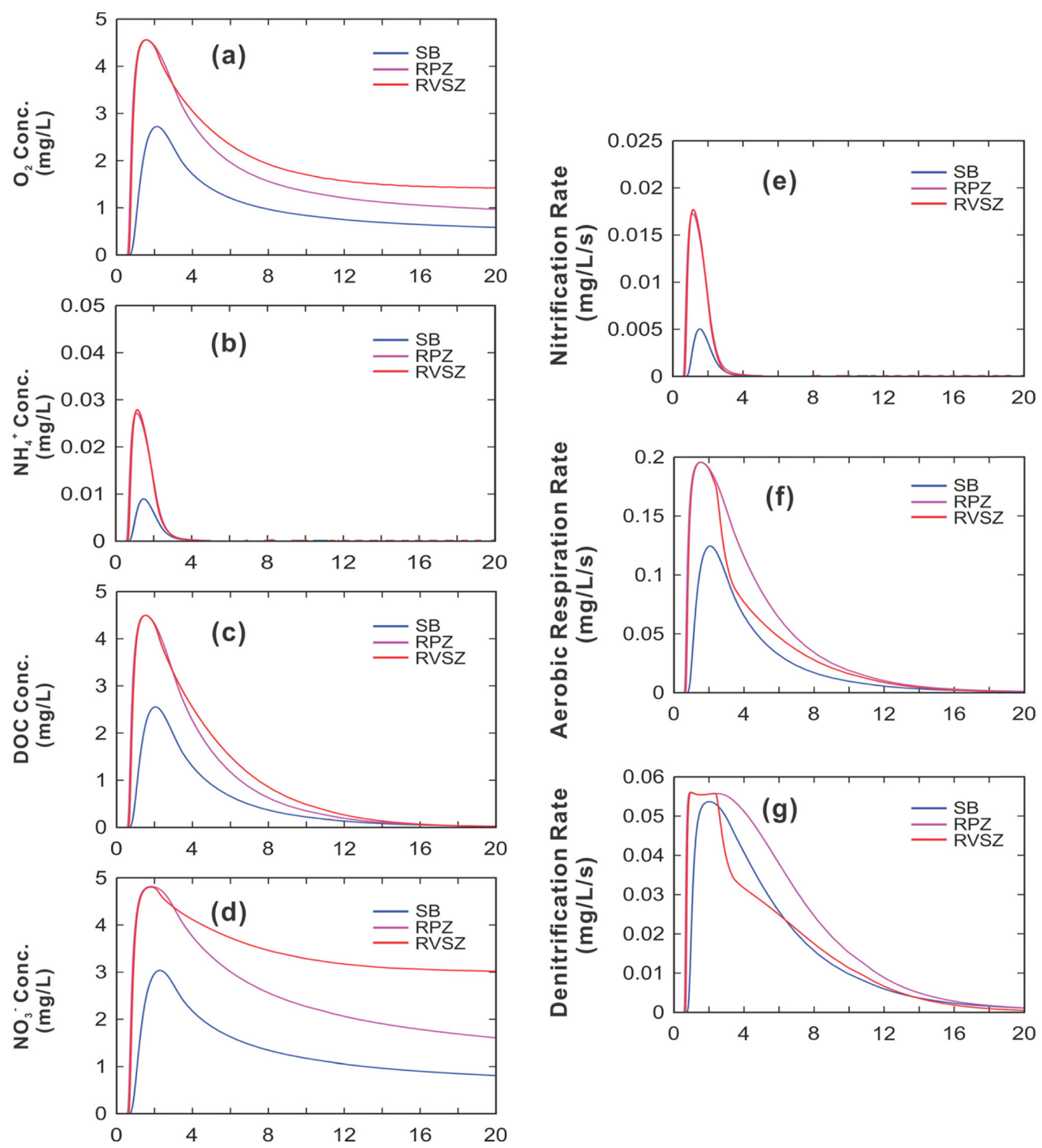

Figure 5. Variations in solute concentration and reaction rate of each solute at different regional observation point units under a flood wave. $S B, R P Z$ and RVSZ denote stream bed, riparian phreatic zone and riparian variable saturated zone, respectively. 


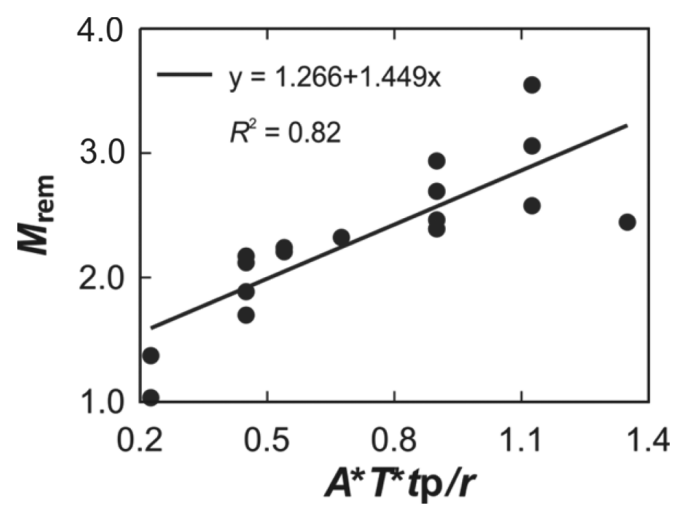

Figure 6. Dimensionless relationship between hyporheic nitrogen $\operatorname{removal}\left(M_{\text {rem-NO3 }}\right)$ and ' $A * T * t_{p} / r$ '.

zone than that being carried into the lateral zone. In the riparian zone, the overall reaction rate of each process in the riparian variable saturated zone was smaller than that in the riparian phreatic zone, because a part of the solute in the variable saturated zone was absorbed by soil particles and remained there, thereby decreasing the overall solute concentrations within the region and reducing the reaction rates.

\section{Implication of a Flood Wave on Hyporheic Nitrogen Removal}

During a flood wave condition, nitrogen removal in the $\mathrm{HZ}\left(M_{\mathrm{rem}-\mathrm{NO} 3}\right)$ was positively correlated with the polynomial ' $A * T * t_{\mathrm{p}} / r$ ' composed of the wave parameters. However, $N_{\text {rem-NO3 }}$ showed the opposite trend

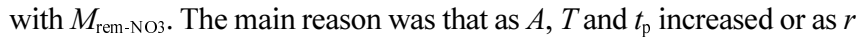
decreased, the aquifer storage increased accordingly, leading to an increase in $M_{\text {in-NO3 }}$ and $M_{\text {rem-NO3 }}$. By comparison, $M_{\text {in-NO3 }}$ increased more than $M_{\text {rem-NO3}}$, which accordingly resulted in the decrease of the ratio of $M_{\text {rem-NO3 }} / M_{\text {in-NO3 }}$ (i.e., $N_{\text {rem-NO3 }}$ ). The relationship between $M_{\text {rem-NO3 }}$ and ' $A * T^{*} t_{\mathrm{p}} / r$ ' can be used to predict the amount of hyporheic nitrogen removal according to an actual flood wave at the site. The amplitude, duration and rising duration of a flood wave are intuitive and easy to measure. The wave type parameter $r$ can be roughly obtained by an empirical polynomial, which is the fitting relationship between ' $\Delta T / T$ ' and $r . \Delta T$ denotes the span of two points at the height of ' $A / 2$ ' on the wave graph.

\section{Conclusions}

This paper systematically studied the hyporheic nitrogen cycles driven by flood waves using a 2D flow-transport-reaction model. The main findings were as follows:

(1) When surface water infiltrated into the aquifer, the solute concentrations in the $\mathrm{HZ}$ increased accordingly, thereby resulting in gradual enhancements of aerobic respiration, nitrification and denitrification, of which aerobic respiration was dominant. When groundwater flowed back, all the chemical reaction processes were gradually weakened, of which the role of denitrification was improved.

(2) In the whole flood duration, solutes in the HZ were continuously consumed, with the consumption in the groundwater-backflow period being greater, although the corresponding reaction rates were slower. In space, the reaction rate of each chemical process from high to low was: riparian phreatic zone $>$ variable saturated zone $>$ stream bed.

(3) A good linear relation existed between the hyporheic nitrogen removal and the polynomial of each parameter ' $A{ }^{*} T^{*} t_{\mathrm{p}} / r$ ', $R^{2}=0.82$. As $A, T$ and $t_{\mathrm{p}}$ increased and $r$ decreased, the nitrogen removal in the $\mathrm{HZ}$ increased accordingly, whereas the removal efficiency showed the opposite trend.

\section{Acknowledgements}

This work is supported by the National Research Foundation of Korea (NRF), funded by the Korea government (MSIT) (No. NRF2015R1A4A1041105), and partly funded by the key project of Nanjing Hydraulic Research Institute (NHRI) (No. Y919005).

\section{References}

Arntzen, E.V., Geist, D.R., and Dresel, P.E., 2006, Effects of fluctuating river flow on groundwater/surface water mixing in the hyporheic zone of a regulated, large cobble bed river. River Research and Applications, v. 22, pp. 937-946. doi: 10.1002/rra.947

Bardini, L., Boano, F., Cardenas, M.B., Revelli, R., and Ridolfi, L., 2012, Nutrient cycling in bedform induced hyporheic zones. Geochimica et Cosmochimica Acta, v. 84, pp. 47-61. doi: 10.1016/j.gca.2012.01.025

Bardini, L., Boano, F., Cardenas, M.B., Sawyer, A.H., Revelli, R., and Ridolfi, L., 2013, Small-scale permeability heterogeneity has negligible effects on nutrient cycling in streambeds. Geophysical Research Letters, v. 40, pp. 1118-1122. doi: 10.1002/grl.50224

Böhlke, J.K., and Denver, J.M., 1995, Combined use of groundwater dating, chemical, and isotopic analyses to resolve the history and fate of nitrate contamination in two agricultural watersheds, Atlantic Coastal Plain, Maryland. Water Resources Research, v. 31, pp. 2319-2339. doi: $10.1029 / 95 \mathrm{wr} 01584$

Chen, X., and Chen, X.H., 2003, Stream water infiltration, bank storage, and storage zone changes due to stream-stage fluctuations. Journal of Hydrology, v. 280, pp. 246-264. doi: 10.1016/S0022-1694(03)00232-4

Curry, R.A., Gehrels, J., Noakes, D.L.G., and Swainson, R., 1994, Effects of river flow fluctuations on groundwater discharge through brook trout, Salvelinus fontinalis, spawning and incubation habitats. Hydrobiologia, v. 277, pp. 121-134. doi: 10.1007/bf00016759

Dahm, C.N., Grimm, N.B., Marmonier, P., Valett, H.M., and Vervier, P., 1998, Nutrient dynamics at the interface between surface waters and groundwaters. Freshwater Biology, v. 40, pp.427-451. doi: 10.1046/j.13652427.1998.00367.x

Fetter, C.W., 2001, Applied hydrogeology (4th edition). Pearson, Upper Saddle River, N.J., 598p. ISBN: 0130882399

Gelhar, L.W., Welty, C., and Rehfeldt, K.R., 1992, A critical review of data on field-scale dispersion in aquifers. Water Resources Research, v. 28, pp. 1955-1974. doi: 10.1029/92wr00607

Gerecht, K.E., Cardenas, M.B., Guswa, A.J., Sawyer, A.H., Nowinski, J.D., and Swanson, T.E., 2011, Dynamics of hyporheic flow and heat transport across a bed-to-bank continuum in a large regulated river. Water Resources Research, v. 47: W03524. doi: 10.1029/2010wr009794

Gu, C.H., Hornberger, G.M., Mills, A.L., Herman, J.S., and Flewelling, S.A., 2007, Nitrate reduction in streambed sediments: Effects of flow and biogeochemical kinetics. Water Resources Research, v. 43, pp. 553-566. doi: 10.1029/2007wr006027

Gu, C.H., Anderson, W., and Maggi, F., 2012, Riparian biogeochemical hot moments induced by stream fluctuations. Water Resources Research, v. 48: W09546. doi: 10.1029/2011wr011720 
Jeon, W.H., and Lee, J.Y., 2015, Seasonal variation of water level, water and soil temperature, chemistry, and stable isotopes in hyporheic zone of Korea. AGU Fall Meeting, 2015, American Geophysical Union, Abstracts ID: H21C-1386.

Hanrahan, T.P., 2008, Effects of river discharge on hyporheic exchange flows in salmon spawning areas of a large gravel-bed river. Hydrological Processes, v. 22, pp. 127-141. doi: 10.1002/hyp.6605

Harvey, J.W., Böhlke, J.K., Voytek, M.A., Scott, D., and Tobias, C.R., 2013, Hyporheic zone denitrification: Controls on effective reaction depth and contribution to whole-stream mass balance. Water Resources Research, v. 49, pp. 6298-6316. doi: 10.1002/wrcr.20492

Hu, H.Z., Binley, A., Heppell, C.M., Lansdown, K., and Mao, X., 2014, Impact of microforms on nitrate transport at the groundwater-surface water interface in gaining streams. Advances in Water Resources, v. 73, pp. 185-197. doi: 10.1016/j.advwatres.2014.07.013

Lee, M.S., Lee, K.K., Hyun, Y., Clement, T.P., and Hamilton, D., 2006, Nitrogen transformation and transport modeling in groundwater aquifers. Ecological Modelling, v. 192(1), pp. 143-159. doi: 10.1016/j.ecolmodel. 2005.07.013

Liu, D.S., Zhao, J., Chen, X.B., Li, Y.Y., Weiyan, S.P., and Feng, M.M., 2018, Dynamic processes of hyporheic exchange and temperature distribution in the riparian zone in response to dam-induced water fluctuations. Geosciences Journal, v. 22, pp. 465-475. doi: 10.1007/s12303017-0065-x

Liu, D.S., Zhao, J., Jeon, W.H., and Lee, J.Y., 2019, Solute dynamics across the stream-to-riparian continuum under different flood waves. Hydrological Processes, v. 33, pp. 2627-2641. doi: 10.1002/hyp.13515

Marzadri, A., Tonina, D., and Bellin, A., 2011, A semianalytical three-dimensional process-based model for hyporheic nitrogen dynamics in gravel bed rivers. Water Resources Research, v. 47: W11518. doi: 10.1029/ 2011wr010583

Molz, F.J., Widdowson, M.A., and Benefield, L.D., 1986, Simulation of Microbial Growth Dynamics Coupled to Nutrient and Oxygen Transport in Porous Media. Water Resources Research, v. 22, pp. 1207-1216. doi: 10.1029/WR022i008p01207

Neuman, S.P., 1990, Universal scaling of hydraulic conductivities and dispersivities in geologic media. Water Resources Research, v. 26, pp. 1749-1758. doi: 10.1029/WR026i008p01749

Roley, S.S., Tank, J.L., and Williams, M.A., 2012, Hydrologic connectivity increases denitrification in the hyporheic zone and restored floodplains of an agricultural stream. Journal of Geophysical Research: Biogeosciences, v. 117: G00N04. doi: 10.1029/2012jg001950

Schulze-Makuch, D., 2005, Longitudinal dispersivity data and implications for scaling behavior. Groundwater, v. 43, pp. 443-456. doi: 10.1111/ j.1745-6584.2005.0051.x

Shuai, P., Cardenas, M.B., Knappett, P.S.K., Bennett, P.C., and Neilson, B.T., 2017, Denitrification in the banks of fluctuating rivers: The effects of river stage amplitude, sediment hydraulic conductivity and dispersivity, and ambient groundwater flow. Water Resources Research, v. 53, pp. 7951-7967. doi: 10.1002/2017wr020610

Stanley, E.H., and Boulton, A.J., 1995, Hyporheic processes during flooding and drying in a Sonoran Desert stream. I. Hydrologic and chemical dynamics. Archivfür Hydrobiologie, v. 134, pp. 1-26.

Sawyer, H.A., Cardenas, M.B., Bomar, A., and Mackey, M., 2009, Impact of dam operations on hyporheic exchange in the riparian zone of a regulated river. Hydrological Processes, v. 23, pp. 2129-2137. doi: 10.1002/hyp.7324

Trauth, N., Musolff, A., Knöller, K., Kaden, U.S., Keller, T., Werban, U., and Fleckenstein, J.H., 2018, River water infiltration enhances denitrification efficiency in riparian groundwater. Water Research, v. 130, pp. 185-199. doi: 10.1016/j.watres.2017.11.058

Voss C.I., 1984, A finite element simulation model for saturated-unsaturated, fluid-density-dependent groundwater flow with energy transport or chemically reactive single-species solute transport. Water Resources Investigations Report (USA), 84-4369. http://pubs.er.usgs.gov/publication/wri844369
Zarnetske, J.P., Haggerty, R., Wondzell, S.M., and Baker, M.A., 2011, Dynamics of nitrate production and removal as a function of residence time in the hyporheic zone. Journal of Geophysical Research: Biogeosciences, v. 116: G01025. doi: 10.1029/2010jg001356

Zarnetske, J.P., Haggerty, R., Wondzell, S.M., Bokil, V.A., and GonzálezPinzón, R., 2012, Coupled transport and reaction kinetics control the nitrate source-sink function of hyporheic zones. Water Resources Research, v. 48: W11508. doi: 10.1029/2012wr011894

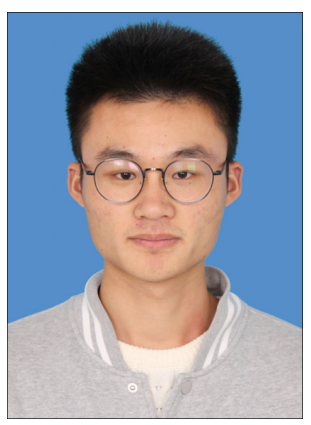

Haoy $\boldsymbol{Z} \boldsymbol{Z h} \boldsymbol{u}$ is a master student of Hydraulic Engineering of School of River and Ocean Engineering, Chongqing Jiaotong University, China. His interests focus on groundwater and surface water environment, hydrobiogeochemical cycling and groundwater modeling.

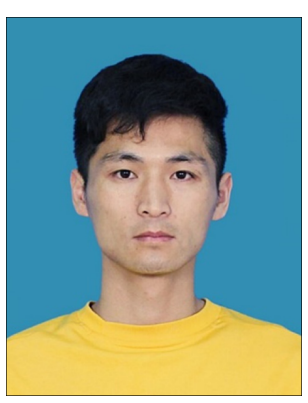

Dongsheng Liu Ph.D. is a postdoctor of Eco-Environmental Research Department, Nanjing Hydraulic Research Institute, China. His research interests involve Engineering Seepage and Groundwater Environment.

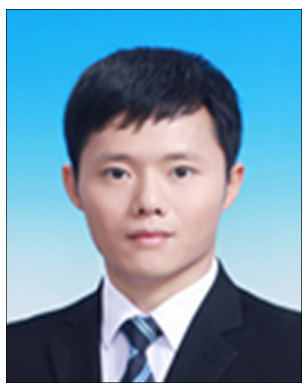

Wenqing Shi Ph.D. is an Environmentist of Eco-Environmental Research Department, Nanjing Hydraulic Research Institute, China. His research interests involve river hydrology, lake eutrophication, lake restoration and nutrient cycles. He has published over 30 research papers in international and Chinese journals.

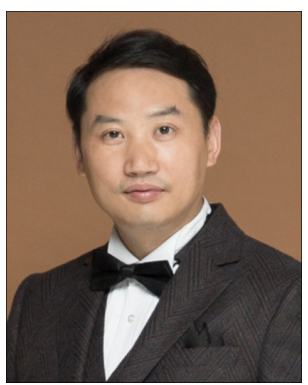

Qiuwen Chen Ph.D. is the director of EcoEnvironmental Research Department, Nanjing Hydraulic Research Institute, China. His interests focus on Ecohydraulics, environmental water informatics and water environment. He has published over 200 research papers in international and Chinese journals. 